\title{
NEW ANALYTICAL METHODOLOGY FOR STUDIES OF TREATMENT PROCEDURES OF LANDFILL LEACHATES - EXPERIENCES FROM A PILOT PLANT STUDY
}

\author{
Lennart Mårtensson ${ }^{l}$ \\ Staffan Bergström ${ }^{2}$ \\ Britt-Marie Svensson ${ }^{1,2}$ \\ Lennart Mathiasson ${ }^{2}$ \\ ${ }^{\prime}$ Kristianstad University, Sweden \\ ${ }^{2}$ Lund University, Sweden
}

\begin{abstract}
In this study we have in pilot scale tested different methods for treatment of leachate from a municipal solid waste (MSW) landfill. Only to focus on sum parameters, nutrients and metals when designing treatment methodology for landfill leachate is not enough, it is also important to measure the content of toxic organic compounds in low concentrations. However, it is not practical to analyse all substances in the leachate and for making evaluation of treatments feasible our own analytical protocol was created. The efficiency of tested treatment procedures was evaluated by measuring changes in concentrations of a number of chosen parameters and organic compounds before and after treatment. The treatment methods tested that showed the highest efficiency towards organic pollutants in leachate were ozone treatment and chemical oxidation with Fenton's reagent. However, more natural based methods like filtering the leachate through a bed with peat mixed with carbon containing bottom-ash showed promising results.
\end{abstract}

\section{INTRODUCTION}

Existing landfills in Europe will pose a threat towards the environment for decades, although new European Union directives favour alternative waste handling methods. By far the most serious problem with landfill is the leaching of a wide variety of toxic compounds and nutrients. Common practice in Sweden is to treat the leachate mixed with other types of wastewaters in municipal wastewater treatment plants. This leads to pollution of the sludge, which then cannot be used for soil improvements. A better approach is to treat the leachate locally at the landfill. Presently such methodology is used only to a small extent and thus there is an increasing need for development of new efficient local treatment systems. The strategy used for evaluation of treatment methods has been difference measurements before and after treatment. The main problem in this context was to decide what to measure. In a complex matrix as leachate it is necessary to choose markers that give the proper information that reflects the effects of different treatment methods. Such markers can be sum parameters 
(e.g. total organic carbon, total nitrogen and total phosphorus), heavy metals or toxic organic compounds.).

\section{EXPERIMENTAL}

\subsection{Evaluation strategy}

Leachate water from landfills has a complex composition. High concentrations of salts and heavy metals often occur simultaneously together with a vast number of different organic compounds. These include polycyclic aromatic hydrocarbons, phthalates, pesticides, and halogenated aromatic compounds as PCBs, polybrominated diphenyl ethers (PBDE), and a variety of phenolic compounds and other priority pollutants [1-7]. US-EPA for example, has characterised more than 400 pollutants in leachate from 13 non-hazardous landfills in USA [7]. Thus, in developing analytical strategies for such complex aqueous samples, there is a need for methodology which includes measurement of charged species as heavy metal ions as well as polar organic pollutants like phenols or non-polar persistent organic pollutants as PCBs. One approach, which incorporates labour intense identification steps for characterisation of polar compounds in leachate. This approach is good, but not completely straight forward for identification of markers.

When evaluating the efficiency of treatment procedures, as in this paper, the analytical procedure can be further simplified, by using relative measurements. In this case, sometimes, only a rough estimate is needed of concentrations of pollutants in the system. This is especially true for all substances, known or unknown, which tend to approach zero, i.e. the more efficient a treatment step is, the less need for absolute values. In order to facilitate the evaluation process we have designed the a analytical protocol in which we divided leachate sample into three parts: 1. Sum parameters including heavy metals; 2. Toxic test using Artemia Salina as test organism [8] and 3 Organic compounds (both polar and unpolar substances.

\subsection{The pilot plant}

A pilot plant was constructed at the Härlöv landfill in the outskirts of the city of Kristianstad, Sweden to be able to compare the efficiencies (based on relative concentration differences before and after treatment) of different technical procedures for leachate treatment.

In the pilot plant the raw leachate water was firstly pre-treated by aeration followed by sedimentation. Then the water was treated by one of four different treatment steps: geofilters, ozonisation, chemical oxidation by Fenton's reagent, and bioremediation.

In this study we have concentrated on the organic content that is less known but has recently drawn much attention. Analytical methodology has been used, which takes into consideration both water-soluble pollutants as phenol compounds and hydrophobic persistent organic compounds. Complementary measurements of metals have also been performed. The treatment methods considered in this study have been biological treatment, chemical oxidation (ozone and Fenton's reagent), and geobed-filter adsorption in a mixture of peat and carbon ash all methods combined with pre-treatment (aeration and sedimentation).

\section{RESULTS AND DISCUSSION}

We have shown that evaluation of treatment systems can be based on the measurements of a limited number of markers, which should include summary parameters, inorganic species and organic compounds of different polarities, The analytical protocol developed gives a sound 
basis for measurements, and a strategy based on difference measurements greatly simplifies the evaluation procedures. However knowledge about the magnitude of pollutant concentration is desirable and that can be achieved by quantification of a limited number of markers in a limited number of samples. Results obtained from identified and quantified marker substances can be supported by measuring also typical but un-identified components in the leachate. It is also desirable that measurements of acute and longterm toxicity is included in the methodology. The chosen methodology will considerably reduce the cost for investigations of complex matrices as leachate from landfills compared to the characterisation procedures commonly used.

The results indicate that the effectiveness towards organic compounds such as phenolic compounds as well as unpolar substances (e.g. PCB. Phtalates etc) were fairly high by using ozone treatment and chemical oxidation. Similar results were also achieved with the use of geobed-filters. This is promising results since the latter technique can be considered as lowtech solutions and can be of importance when implementing sustainable methods for treatment of landfill leachate in developing countries with poor economical and technical circumstances. Use of geobed-filters also a feasible way of controlling emission of pollutants from landfills in industrialised country. This has been shown in other pilot plant and full scale studies within our research group [9].

We have also experienced higher concentrations of some metals in the outgoing water after treatment that is due release from the material in the equipment of the pilot plant. This was especially found for zink from bioremediation and copper from ozonation. Thus, to design the treatment plant with the best order between different treatment steps it is necessary to have good knowledge of the situation in all steps individually.

\section{REFERENCES}

[1] Asakura, H., Matsuto, T., Tanaka, N., 2004. Behaviour of endocrine-disrupting chemicals in leachate from MSW landfill sites in Japan. Waste Management 24, 613622.

[2] Baun, A., Ledin A., Reitzel, L., 2004. Xenobiotic organic compounds in leachates from ten Danish MSW landfills - chemical analysis and toxicity tests. Water Research 38 , 3845-3858.

[3] Slack, R.J., Gronow, J.R., Voulvoulis, N., 2005. Household hazardous waste in municipal landfills: contaminants. Science of the Total Environment 337, 119-137.

[4] Paxéus N. (2000) Organic compounds in municipal landfill leachates. Water Science and Technology 42(7-8), 323-333

[5] Thörneby, L. Mathiasson, L., Mårtensson, L., Hogland, W., 2005. The performance of the soil-plant treatment systems for landfill systems with special emphasis on the fate of organic pollutants. Waste Management Research (in press).

[6] Öman, C., 1998. Emissions of organic compounds from landfills. Doctoral thesis. TRITA-AMI PHD 102. Royal Technical Institute, Stockholm, Sweden.

[7] US EPA, 2000. Environmental Assessment for Final Effluent Limitations Guidelines and Standards for the landfills Point Source Category. EPA-821-B99-006. US EPA.

[8] Svensson, B-M., Mathiasson, L., Mårtensson, L., Bergström, S., 2005. Artemia Salina as test organism for assessment of acute toxicity of leachate water from landfills. Environmental Monitoring and Assessment 102, 309-321.

[9] Hogland, W. Kängsepp, P., Mathiasson, L.e, Mårtensson, L., Svensson, B-M, Thörneby, L. And Bergström, S., 2002. Analysis and treatment of persistent orgsanics in leachate from industrial landfills. In: International Waste Biennal Congress and Exhibition. 30 September-4 October 2002, Durban, South Africa. Volume 1, pp. 205-212. 